\title{
Comparison of satellite microwave backscattering (ASCAT) and visible/near-infrared reflectances (PARASOL) for the estimation of aeolian aerodynamic roughness length in arid and semi-arid regions
}

\author{
C. Prigent, C. Jiménez, and J. Catherinot \\ CNRS - UMR8112, Laboratoire d'Etudes du Rayonnement et de la Matière en Astrophysique, \\ Observatoire de Paris, Paris, France \\ Correspondence to: C. Prigent (catherine.prigent@obspm.fr)
}

Received: 6 February 2012 - Published in Atmos. Meas. Tech. Discuss.: 17 April 2012

Revised: 6 October 2012 - Accepted: 16 October 2012 - Published: 13 November 2012

\begin{abstract}
Previous studies examined the possibility to estimate the aeolian aerodynamic roughness length from satellites, either from visible/near-infrared observations or from microwave backscattering measurements. Here we compare the potential of the two approaches and propose to merge the two sources of information to benefit from their complementary aspects, i.e. the high spatial resolution of the visible/near-infrared $(6 \mathrm{~km}$ for PARASOL that is part of the A-Train) and the independence from atmospheric contamination of the active microwaves (ASCAT on board MetOp with a lower spatial resolution of $25 \mathrm{~km}$ ). A global map of the aeolian aerodynamic roughness length at $6 \mathrm{~km}$ resolution is derived, for arid and semi-arid regions. It shows very good consistency with the existing information on the properties of these surfaces. The dataset is available to the community, for use in atmospheric dust transport models.
\end{abstract}

\section{Introduction}

Aeolian aerodynamic roughness length in arid regions is a key parameter to predict the vulnerability of the surface to wind erosion, and, as a consequence, the related production of mineral aerosol (e.g. Raupach et al., 1993; Marticorena et al., 1997; Marticorena and Bergametti, 1995; Tegen et al., 2000; Shao, 2001; Laurent et al., 2008; Todd et al., 2008). Aerodynamic roughness length is defined as the height where the wind speed becomes zero, assuming a logarithmic wind profile. It affects both the quantity of potentially eroded material and the minimum wind speed required to raise the dust particles (Gillette and Passi, 1988). Physical models of mineral dust emissions have thus been developed based on an explicit description of the main physical processes involved during dust production (e.g. Marticorena and Bergametti, 1995; Shao, 2001; Alfaro and Gomes, 2001). They include parameterizations of the erosion threshold as a function of the surface roughness parameters. However, the use of such physical models are limited by the availability of datasets characterizing the surface features of the arid and semi-arid areas, especially their aerodynamic roughness length (Laurent et al., 2008; Darmenova et al., 2009). Recent dust model intercomparisons (e.g. Uno et al., 2006; Todd et al., 2008; Darmenova et al., 2009) emphasize the need for improved dust emission modeling, along with their key input parameters, including the roughness parameters, to accurately quantify the role of mineral aerosol in a changing climate. Note that the dust emission scheme requires parameters at spatial and temporal scales relevant to dust emission: the aerodynamic roughness length used by regional and global land surface models are not relevant to the dust emission processes (Darmenova et al., 2009).

The aeolian roughness length is difficult to estimate, even locally. In situ measurements usually consist in measuring the wind velocity profile from several anemometers on a mast, in near-neutral stability conditions (e.g. Greeley et al., 1997; MacKinnon et al., 2004). Marticorena et al. (1997) and Callot et al. (2000) developed maps of aerodynamic roughness length for North Africa and the Middle East, based on a geomorphological approach that combines topographic data, geological information, aerial pictures, and in 

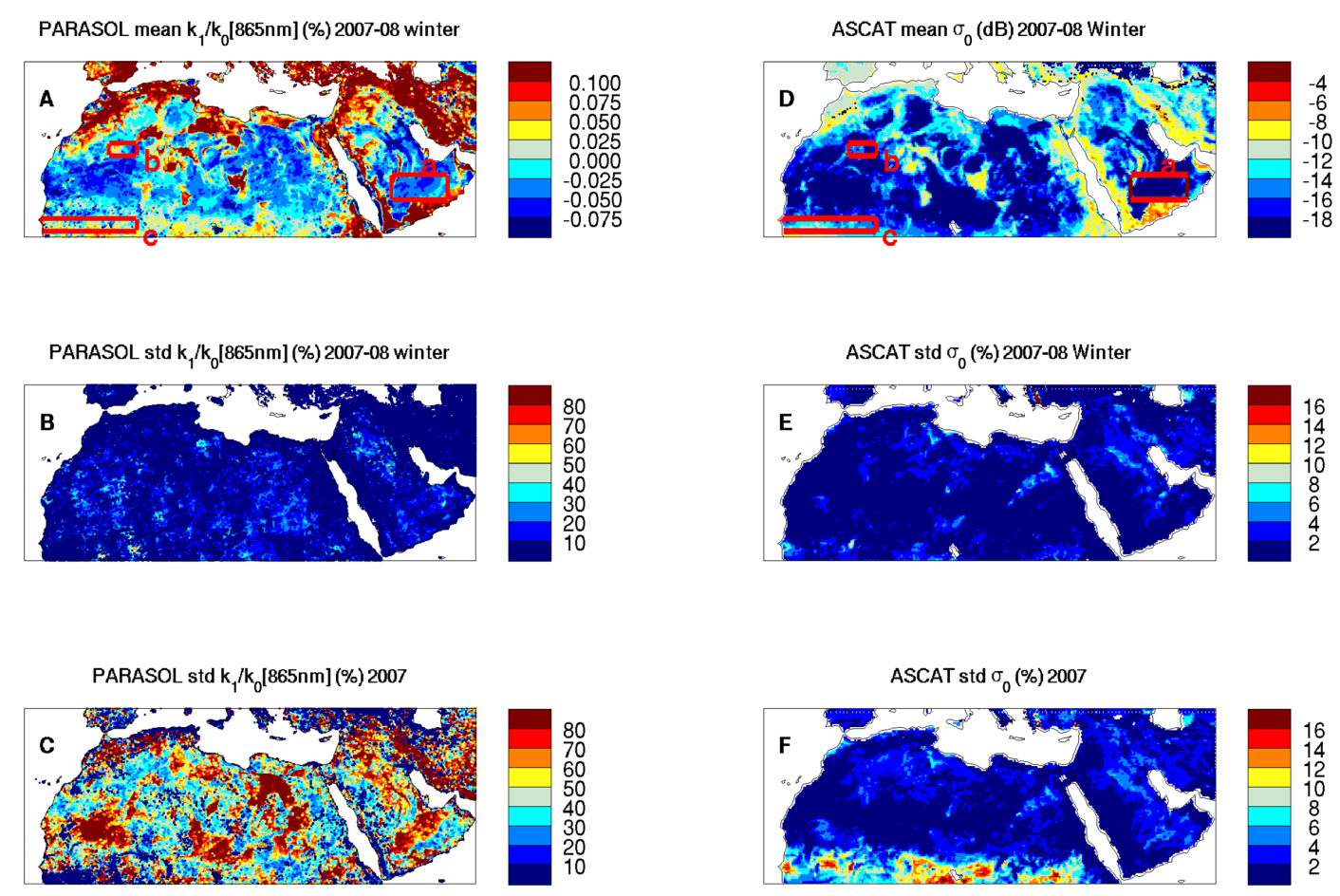

Fig. 1. Left panels: the PARASOL mean $k_{1} / k_{0}$ at $865 \mathrm{~nm}$ over the 2007-2008 winter months (A), along with the variability of the $k_{1} / k_{0}$ (calculated as the standard deviation over the mean $k_{1} / k_{0}$ value in percentage) for the 2007-2008 winter months (B) and for the full 2007 year $(\mathbf{C})$. Right panels: same for the ASCAT $\sigma_{0}(\mathbf{D}, \mathbf{E}, \mathbf{F})$. Three regions $(\mathrm{a}, \mathrm{b}, \mathrm{c})$ are selected - on (A) and (D) - for a further analysis of the temporal variability (see Fig. 2). The regions cover the following areas: zone "a" from latitude 18 to 22 , longitude 45 to 55 , zone "b" from latitude 25 to 27 , longitude -5 to 0 , zone "c" latitude 13 to 15 , longitude -17 to 0 .

situ observations. Satellite observations are an effective solution for a global homogeneous and systematic monitoring of the arid and semi-arid regions. Radar observations are sensitive to surface roughness, among other parameters. Greeley et al. (1997) demonstrated a high correlation between $z_{0}$ and the radar backscattering using observations from aircraft and from the Shuttle Radar Laboratory at 1.4 and $5.25 \mathrm{GHz}$ in coincidence with field measurements. More recently, Prigent et al. (2005) derived global maps of aerodynamic roughness lengths in arid and semi-arid regions from the scatterometer measurements on board ERS. The estimates are provided with a spatial resolution of $0.25^{\circ} \times 0.25^{\circ}$, on a monthly basis. The scatterometer spatial resolution is limited $(50 \mathrm{~km})$ but the observations are almost insensitive to atmospheric contamination. Visible and near infrared observations are also sensitive to the surface roughness. The basis of this estimation has been established early (Lettau, 1969). This parameter has been estimated from measurements with the POLarization and Directionality of the Earth Reflectance (POLDER) instrument on board ADEOS I, first over North Africa (Roujeau et al., 1997; Marticorena et al., 2004), and then over Asian deserts (Laurent et al., 2005). Given that the bidirectional reflectance in arid regions decreases with the shading effect of roughness elements like stones and pebbles, an empirical relationship is derived between the observed bidirectional reflectances and the roughness estimates from in situ measurements (Greeley et al., 1997) and from the geomorphological maps (Marticorena et al., 1997). The limitation of this method is the high sensitivity of the observations to clouds as well as to aerosols in the atmospheric column, with severe impact especially in the regions that are particularly productive in aerosols (see Fig. 1 in Laurent et al., 2005). In addition, the very limited acquisition period on both ADEOS 1 and 2 hampered the production of global maps for the various seasons. However, compared to scatterometer data, visible and near-infrared data can provide higher spatial resolution, below $10 \mathrm{~km}$ resolution. Extensive modeling efforts have been directed toward a better understanding of the mechanisms responsible for satellite responses of bare soil, in the visible/near infrared or in the microwaves (e.g. Roujean et al., 1992 in the visible/near infrared, and Fung et al., 1992 in the microwaves). Although the gross behavior of the surface observations can usually be interpreted by simulations, it is difficult to have satisfactory agreement between the real observations and simulations. The major problems are related first to the difficulty of a model to account for all the interactions between the surface and potentially its subsurface and second to the difficulty to describe the real surface characteristics, especially its roughness. Our objective is to provide the aerosol modeling 
community with global maps of roughness length. For this, we need to find a practical relationship between the satellite observations and the aeolian aerodynamic roughness length, on a global basis for arid and semi-arid regions. A direct statistical relationship will be established between the available reliable roughness length estimates and the two sources of satellite observations that already showed a good potential to map roughness length at a global scale, namely the visible/near-infrared reflectances (here from PARASOL) and the scatterometer backscattering (here from ASCAT).

The satellite observations are presented in Sect. 2, along with the in situ measurements used in this study. In Sect. 3, a relationship is derived between the visible/near-infrared and the microwave satellite observations and the in situ aerodynamic roughness length, first using the satellite observations separately then merging them. Global results are presented in Sect. 4 and are compared with existing land surface characterization. Section 5 concludes this study.

\section{Datasets}

\subsection{PARASOL visible/near-infrared satellite observations}

PARASOL is a wide-field imaging radiometer/polarimeter, launched in December 2004 (Tanré et al., 2011). This microsatellite is part of the A-Train. PARASOL is similar to the instruments POLDER- 1 and 2 that were on the ADEOS platforms; unfortunately the lifetime of both POLDER instruments was limited to less than one year.

PARASOL has 9 channels operating from the blue $(443 \mathrm{~nm})$ through the near-infrared $(1020 \mathrm{~nm})$. The pixel size is $5.3 \mathrm{~km} \times 6.2 \mathrm{~km}$ at nadir. In this study, observations at 443 , $565,670,765$, and $865 \mathrm{~nm}$ are analyzed (the longer wavelengths are more sensitive to the atmosphere, without bringing additional information on the surface characteristics). The reflectances are first calibrated. For land surface characterization purposes, the signals are corrected from most atmospheric effects, except aerosols and potentially undetected clouds (Maignan et al., 2004; Leroy et al., 1997). A semi-empirical bidirectional reflectance model is adopted, to fit the time series of the calibrated and corrected reflectances (Roujean et al., 1992; Maignan et al., 2004): it combines the directional reflectance of a flat surface with randomly and oriented protrusions with the contribution of the radiative transfer within the vegetation canopy. This model is simple enough to require a limited number of observations per pixels, and yet sufficiently complex to account for the major physical processes at play. The bidirectional reflectance is expressed by

$R\left(\theta_{\mathrm{s}}, \theta_{\mathrm{v}}, \phi\right)=k_{0}+k_{1} \times \mathrm{F} 1\left(\theta_{\mathrm{s}}, \theta_{\mathrm{v}}, \phi\right)+k_{2} \times \mathrm{F} 2\left(\theta_{\mathrm{s}}, \theta_{\mathrm{v}}, \phi\right)$

where F1 and F2 estimate the directional reflectance of a flat surface with protrusions and vegetation canopy, respectively; $k_{0}, k_{1}, k_{2}$ are the fit parameters; and $\theta_{\mathrm{s}}, \theta_{\mathrm{v}}$, and $\phi$ are the solar zenith, view zenith, and relative azimuth angles, respectively. More details about this parameterization of the reflectance is given in Maignan et al. (2004).

Monthly $k_{0}, k_{1}, k_{2}$ parameters are provided for PARASOL: a grid point has to be observed at least 5 times during the month to be considered (each satellite overpass provides up to 16 successive measurements of the same target thanks to the multi-directional capabilities of the instrument). Four years of PARASOL directional reflectances have been analyzed (2005-2008). Following the modeling and analysis by Roujean et al. (1992) and the study by Marticorena et al. (2004) and Laurent et al. (2008), the coefficient $k_{1} / k_{0}$ (called the protrusion coefficient) characterizes the surface roughness, although a direct and physical link between this coefficient and the aeolian aerodynamic roughness length cannot be mathematically described at $6 \mathrm{~km}$ pixel size. Over arid regions, the protusion coefficients are expected to be stable in time. However, our analysis evidences that the $k_{1} / k_{0}$ coefficients can undergo significant variability, especially during spring and summer months in the Northern Hemisphere. This is partly related to the presence of aerosol in the atmospheric column at this time of the year (no aerosol correction has been applied to the data). Marticorena et al. (2004) also observed this variability increase in POLDER data and decided to use winter observations only for their analysis of the aerodynamic roughness length. Figure 1 (left panels) shows the mean $k_{1} / k_{0}$ coefficient for the 2007-2008 winter in the Northern Hemisphere (November to February), along with the variability of this product over the winter and over the full 2007 year at $865 \mathrm{~nm}$, for North Africa and the Arabian Peninsula. The variability is calculated as the standard deviation of the $k_{1} / k_{0}$ over the mean $k_{1} / k_{0}$, in percentage. Contrarily to POLDER (Laurent et al., 2008), PARASOL provides quality data almost globally, during the winter months. The $k_{1} / k_{0}$ coefficient should be independent from the wavelength (Roujean et al., 1992). We checked that the correlations between 670,765 , and $865 \mathrm{~nm}$ were high in winter (over 0.85), but lower during the rest of the year, due to aerosol-related noise in the data. The $k_{1} / k_{0}$ coefficients for the shorter wavelengths are much noisier, and their correlation with the parameters at other wavelengths is consequently decreased (below 0.7 ). For three different zones - a sand desert area (a), a rocky desert region (b), and a semi-arid zone (c) - in the studied area, Fig. 2 (upper panels) shows the 2007 monthly mean time series of the $k_{1} / k_{0}$ parameters for PARASOL wavelengths. Missing data during summer months are related to aerosol contamination during the dust season. The largest variability of the shorter wavelengths is clear. In the third region (right), some variability in the coefficient can also be observed even at the longer wavelengths: this variability cannot be clearly related to vegetation phenology, as it is out of phase with the Normalized Difference Vegetation Index (NDVI) and the scatterometer responses to the vegetation (lower panels). For this study, 

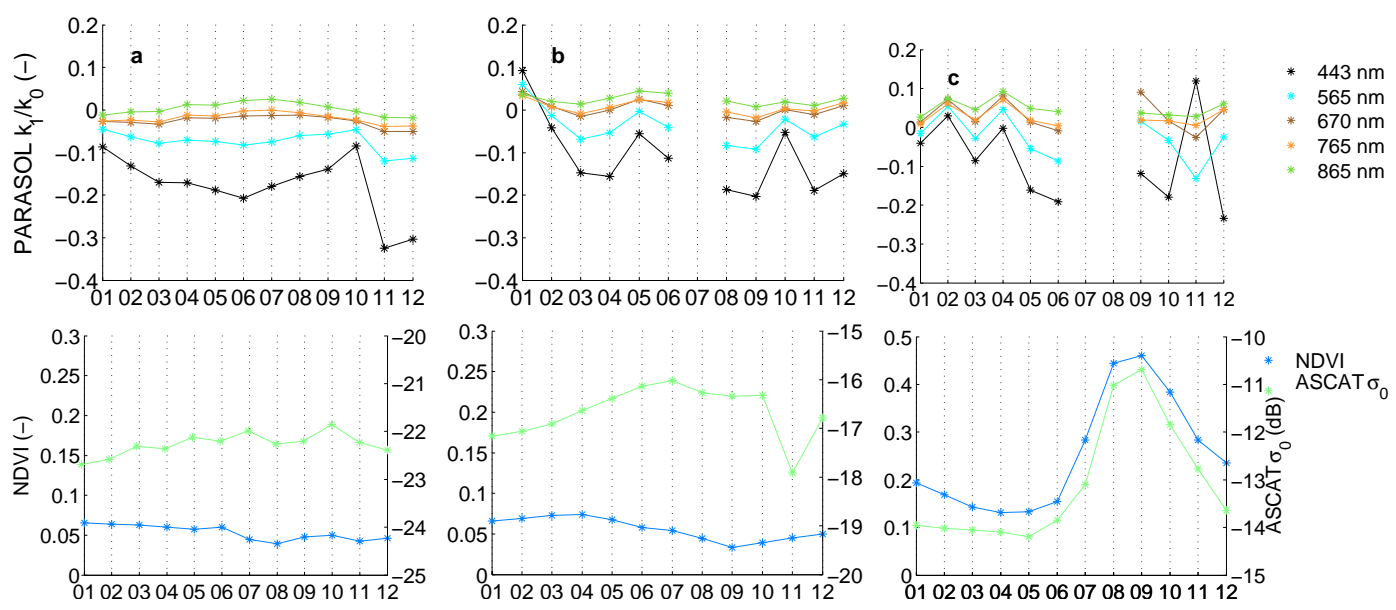

Fig. 2. Top panels: time series of the mean $k_{1} / k_{0}$ for all PARASOL wavelengths, for the three regions selected on Fig. $1-(\mathbf{a})-(\mathbf{c})$, from left to right panels - for 2007. Lower panels: similar time series of the ASCAT response at 5.25 GHz along with the NDVI.

the $865 \mathrm{~nm}$ observations during the 2007 winter months will be used: the different channels are highly correlated, with the $865 \mathrm{~nm}$ presenting the lowest noise level. Other parameters potentially related to the roughness have been examined, such as a bi-directionality index that represents the difference of the reflectances backward and forward over their sum, but these parameters are very correlated with the $k_{1} / k_{0}$ coefficient ( $\sim 0.9$ for the longer wavelengths), without any significant reduction in the noise level as compared to $k_{1} / k_{0}$.

\subsection{ASCAT scatterometer satellite measurements}

Active microwave observations over the entire globe have been available since 1991, from the ERS scatterometer at $5.25 \mathrm{GHz}$ (1991 to 2001), from QuickScat at $13.4 \mathrm{GHz}$ (1999-2009), and more recently from ASCAT at $5.25 \mathrm{GHz}$ on board the European meteorological satellite MetOp since 2006. In this study, ASCAT data are used. ASCAT is the improved successor to the ERS scatterometer. Measurements at $5.25 \mathrm{GHz}$ are affected very little by the atmosphere, and no contamination by the aerosols is expected. Two sets of three antennas record the backscattering signals in different directions, two of them point perpendicularly to the satellite track and the four others at $45^{\circ}$ respectively two forward and two backward, to make observations in two $500 \mathrm{~km}$ wide swaths on each side of the satellite ground track. The ASCAT provides measurements at $50 \mathrm{~km}$ spatial resolution, sampled every $25 \mathrm{~km}$. First, the data are gridded on an equal area grid of $0.25^{\circ} \times 0.25^{\circ}$ at the equator. For each grid cell, a linear fit between the ASCAT backscattering coefficient $\sigma_{o}$ and the incident angle is calculated for a month and the fitted value at $45^{\circ}$ is kept, similar to the approach adopted for the analysis of the ERS scatterometer in Prigent et al. (2005). This preprocessing procedure is necessary as each grid cell is not observed frequently enough under a single incidence angle for a robust estimate for each angle separately. Figure 1 (right panels) represents the mean value of the backscattering coefficient at $45^{\circ}$ for the winter 2007-2008 in the Northern Hemisphere (November to February), for North Africa and the Arabian Peninsula, along with the standard deviation of the information over the winter and over the full year. The scatterometer data are very stable over time in the arid regions, with standard deviation of the order of the expected instrument noise (below $0.5 \mathrm{~dB}$ ), in the arid regions. Over semiarid regions, the scatterometer is sensitive to the presence of even sparse vegetation, with an increase of the backscattering $\sigma_{o}$ with increasing vegetation density. This is confirmed in Fig. 2, with very stable responses in the two desert regions (a and b), and a variability strongly correlated with the NDVI changes over the semi-arid area in the sub-Sahelian zone (c).

\subsection{In situ data}

Two types of $z_{0}$ in situ estimates are collected for comparisons with the satellite observations. These two sources of data have already been adopted in Marticorena et al. (2004, 2006) and in Prigent et al. (2005). The first source consists of $z_{0}$ estimates from wind profile obtained by Greeley et al. (1997) over Death valley, Nevada and Namibia. Since many measurements are performed locally for each site, the $z_{0}$ mean value is computed for each one (G07 in Table 1). The second type of $z_{0}$ estimates is derived from the geomorphologic methodology developed by Callot et al. (2000) for the Sahara and the Arabian Peninsula: it produces a map at $1^{\circ} \times 1^{\circ}$ spatial resolution. Homogeneous regions have already been selected from these geomorphologic estimates, for comparisons with satellite data (M04 and M06 in Table 1). In Marticorena et al. (2006), in situ $z_{0}$ estimates from both methods (in situ and geomorphological) have been compared and they show very good agreement (correlation of 0.90): the geomorphologic estimates are reported in Table 1 for this campaign (M06 in Table 1). Xian et al. (2002) 
Table 1. Aeolian aerodynamic roughness length in situ estimates from pedological observations (Marticorena et al., 2004, M04 in the table), and from wind profile estimates (Greeley et al., 1997, G07; and Marticorena et al., 2006, M06).

\begin{tabular}{crrrcccc}
\hline lat. max & long. min & lat. min & long. max & $z_{0}(\mathrm{~cm})$ & Ref. & $z_{0}$ from Parasol & $z_{0}$ from ASCAT \\
\hline 20.73 & -9.73 & 20.30 & -9.30 & 0.002 & M04 & 0.0017 & 0.0082 \\
31.60 & 7.00 & 31.23 & 7.42 & 0.002 & M04 & 0.0041 & 0.0110 \\
21.80 & -7.70 & 21.33 & -7.25 & 0.002 & M04 & 0.0029 & 0.0074 \\
31.65 & 8.56 & 31.22 & 9.05 & 0.002 & M04 & 0.0068 & 0.0126 \\
23.70 & 0.98 & 23.30 & 1.36 & 0.010 & M04 & 0.0202 & 0.0131 \\
26.20 & -7.48 & 25.80 & -7.30 & 0.025 & M04 & 0.0305 & 0.0135 \\
21.70 & 5.33 & 21.25 & 5.80 & 0.050 & M04 & 0.0395 & 0.0171 \\
21.66 & 4.33 & 21.35 & 4.80 & 0.050 & M04 & 0.0507 & 0.0243 \\
30.70 & 11.15 & 30.25 & 11.20 & 0.150 & M04 & 0.1547 & 0.1804 \\
30.16 & 10.75 & 29.75 & 11.20 & 0.150 & M04 & 0.1819 & 0.2591 \\
25.70 & 8.16 & 25.30 & 8.53 & 0.500 & M04 & 0.4577 & 0.2606 \\
33.60 & -1.30 & 33.20 & -0.80 & 0.873 & M04 & 0.0688 & 0.0830 \\
26.42 & -4.90 & 26.30 & -4.45 & 0.050 & M04 & 0.0853 & 0.0852 \\
25.70 & 8.16 & 25.26 & 8.62 & 0.500 & M04 & 0.4577 & 0.2488 \\
26.20 & 8.28 & 25.76 & 8.53 & 0.500 & M04 & 0.5541 & 0.3499 \\
33.63 & 2.88 & 33.20 & 3.50 & 0.347 & M04 & 0.1600 & 0.0696 \\
33.62 & 3.52 & 33.20 & 4.02 & 0.347 & M04 & 0.2882 & 0.1430 \\
26.98 & -3.73 & 26.76 & -3.15 & 0.131 & M04 & 0.0816 & 0.0596 \\
27.78 & -8.72 & 27.46 & -8.28 & 0.131 & M04 & 0.1163 & 0.1140 \\
28.68 & 2.67 & 28.15 & 2.92 & 0.087 & M04 & 0.2986 & 0.2682 \\
29.77 & 2.97 & 29.23 & 3.58 & 0.087 & M04 & 0.2126 & 0.1951 \\
23.83 & -8.37 & 23.45 & -7.62 & 0.017 & M04 & 0.0388 & 0.0176 \\
22.50 & 0.62 & 22.28 & 0.88 & 0.010 & M04 & 0.0272 & 0.0127 \\
-23.40 & 14.73 & -23.6 & 14.93 & 0.023 & M04 & 0.0832 & 0.0098 \\
36.43 & -116.90 & 36.23 & -116.70 & 0.369 & G07 & 0.5959 & 0.8412 \\
38.38 & -116.25 & 38.13 & -116.00 & 0.015 & G07 & 0.1298 & 0.3840 \\
33.26 & 10.47 & 33.26 & 10.47 & 0.480 & M06 & 0.1311 & 0.1449 \\
33.45 & 9.24 & 33.45 & 9.24 & 0.250 & M06 & 0.0272 & 0.0338 \\
33.25 & 9.97 & 33.25 & 9.97 & 0.170 & M06 & 0.2033 & 0.1658 \\
\hline & & & & & & &
\end{tabular}

performed $z_{0}$ in situ measurements over the Gobi desert in a valley of $400 \mathrm{~m}$ width: we attempted to use this dataset as well, but the spatial resolution of our satellite data and their high sensitivity to orography made the comparison with in situ measurements meaningless in such heterogeneous and mountain environments. It has been verified that the aeolian roughness lengths reported in Table 1 are also compatible with results obtained in wind tunnels over bare surfaces (Xian et al., 2002; Sherman and Farrell, 2008).

\section{Relationship between satellite data and in situ roughness measurements}

The comparison between the satellite and the in situ observations is limited to a period of time when both satellite data are available, with a quality compatible with our objective of estimating the roughness length. The Northern Hemisphere winter 2007-2008 is selected: both PARASOL and ASCAT data are available and PARASOL is little affected by atmospheric aerosols during that season (see Sect. 2). We are aware that the roughness length can undergo temporal variability, related to vegetation, to agricultural activities, or even to changes in dune patterns or to dust deposition following an aerosol event. It is possible to have multi-temporal estimates of the roughness length from active microwaves (Prigent et al., 2005), but due to the atmospheric contamination for the visible observations over a long period of time during the year, we will limit our analysis here to mean values for the November-February period, when the atmospheric contamination is minimum in the Northern Hemisphere. In this section, the PARASOL observations are considered at their nominal $6 \mathrm{~km}$ spatial resolution, and the ASCAT data at $\sim 25 \mathrm{~km}$ spatial resolution.

\subsection{PARASOL data versus aeolian roughness length}

Previous studies (Marticorena et al., 1997, 2004, 2006; Laurent et al., 2005, 2006, 2008) evidenced the logarithmic relationship between $z_{0}$ and $k_{1} / k_{0}$ over arid surfaces. Figure 3 (upper panel) illustrates this log linear relationship between $z_{0}$ and PARASOL $k_{1} / k_{0}$ parameter at $865 \mathrm{~nm}$. When the $z_{0}$ in situ estimates are not point measurements, but are representative of an area, all PARASOL pixels within this area 

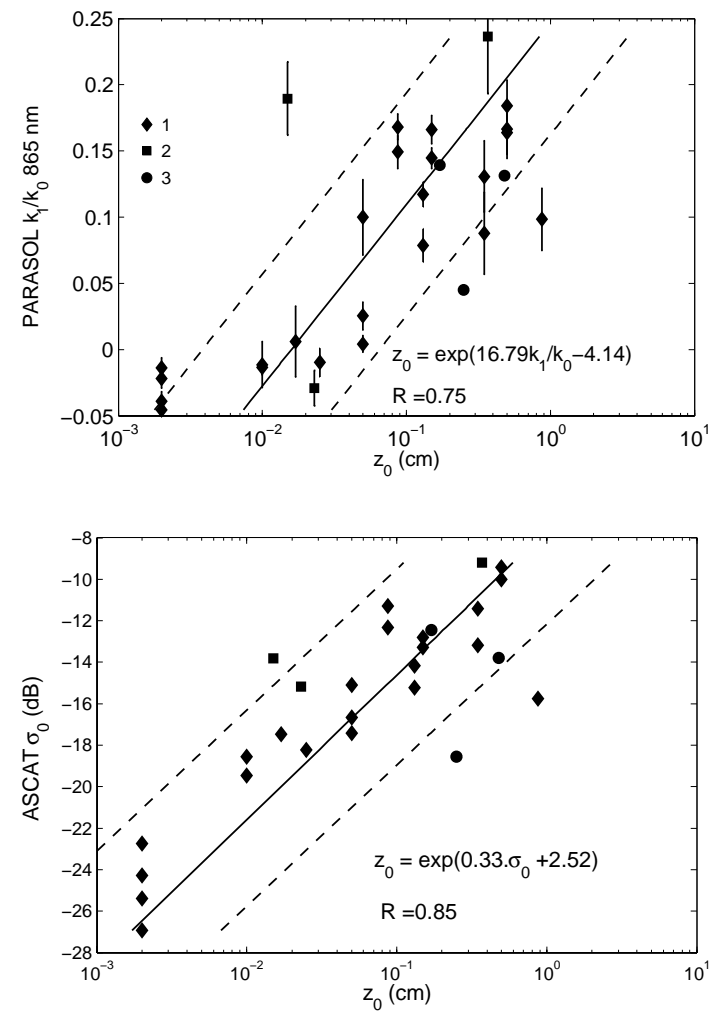

Fig. 3. Scatter plot of the selected $z_{0}$ estimates (see Table 1) versus the $k_{1} / k_{0}$ PARASOL coefficient at $865 \mathrm{~nm}$ (top panel) and the ASCAT $\sigma_{0}$ (bottom panel). For PARASOL, bars indicate the standard deviation over the area. The solid line indicates the regression line, and the dashed lines the regression line plus and minus one standard deviation with respect to the observations. Diamond shapes (1) for Marticorena et al. (2004), squares (2) for Greeley et al. (1997), and circle (3) for Marticorena et al. (2006).

are averaged (their mean and their std dev are indicated on Fig. 3). We verified that similar regressions are obtained with the other PARASOL channels that are highly correlated (see Sect. 2). $56 \%$ of the variance is explained by this $\log$ linear relationship. Note that the regression parameters estimated in this study are similar to those obtained by Marticorena et al. (2004) with POLDER, although the instruments and the time periods are different.

\subsection{ASCAT data versus aeolian roughness length}

Greeley et al. (1997) showed the existence of a log linear relationship between $z_{0}$ and the backscattering $\sigma_{o}$ at local scale and Prigent et al. (2005) confirmed it for the arid and semiarid regions, globally. The basis for this relation relies on a high sensitivity of $\sigma_{o}$ to the surface roughness when incidence angle values are above $\sim 35^{\circ}$. Other factors can interfere with the signal, such as volume scattering in sandy desert or variations of the dielectric properties. The results from Prigent et al. (2005) with the ERS scatterometer were very encouraging and tended to show that the surface roughness

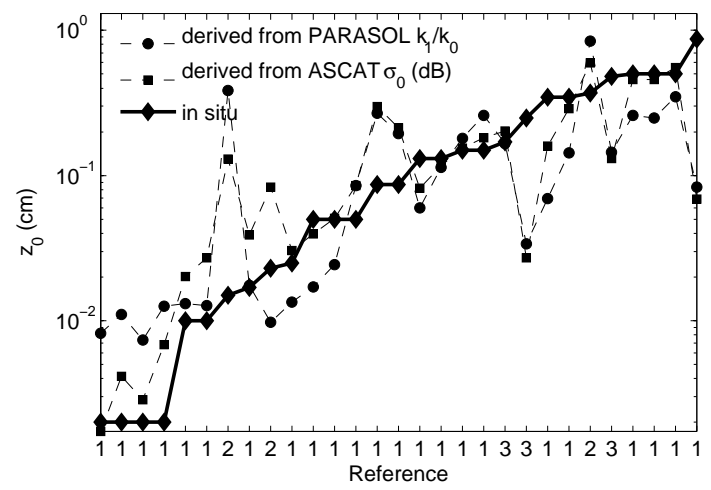

Fig. 4. Scatter plot of the modeled $z_{0}$ estimates using ASCAT and PARASOL, versus the sorted in situ $z_{0}$ values (see Table 1). Reference 1 for Marticorena et al. (2004), 2 for Greeley et al. (1997), and 3 for Marticorena et al. (2006).

dominates the signal in the arid and semi-arid regions. Figure 3 (lower panel) shows the log linear relationship between $z_{0}$ and $\sigma_{o}$ for the ASCAT observations at $25 \mathrm{~km}$ spatial resolution, using the closest ASCAT 2007-2008 winter averaged observations to the in situ measurement. This regression explains $72 \%$ of the $\sigma_{o}$ variance. Despite the change in instrumentation (ERS to ASCAT), this relationship is very similar to the previously obtained one (Prigent et al., 2005), as expected.

\subsection{Merging PARASOL and ASCAT data to estimate aeolian roughness length}

Visible/near-infrared observations (PARASOL) can provide $z_{0}$ estimates at high spatial resolution, which is desirable for dust modeling at regional scale. However, these data are subject to contamination by clouds and aerosols, with quasi persistent missing data or low quality information in some regions. From scatterometer observations (ASCAT), robust $z_{0}$ estimates can be derived, with no contamination from the atmosphere, but with limited spatial resolution as compared to the visible/near-infrared estimates.

Figure 4 compares the estimates from PARASOL and ASCAT, sorted by increasing values of the corresponding in situ data. A good correspondence is obtained between the two satellite products, despite their different spatial resolutions: the agreement between the two satellite estimates is actually better than the agreement between each satellite estimate and the in situ measurements from which the regression has been derived. The linear correlation between the two $z_{0}$ retrieved parameters is equal to 0.91 , i.e. higher than the correlations between the in situ $z_{0}$ and each satellite information separately ( 0.75 for PARASOL, and 0.85 for ASCAT). For pixels with a disagreement between the in situ data and one satellite, the two satellite values agree well. Note that the uncertainty on the in situ $z_{0}$ estimate is not known and would be very difficult to assess. The good consistency between the two 


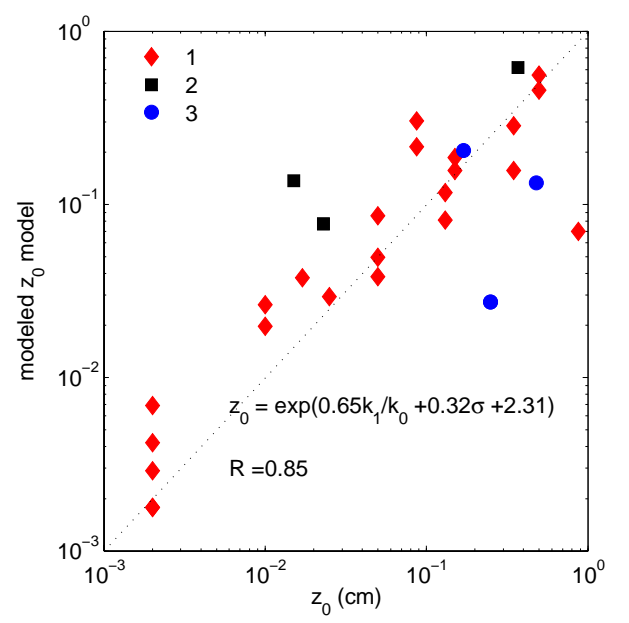

Fig. 5. Scatter plot of the modeled $z_{0}$ estimates using ASCAT and PARASOL simultaneously, versus the in situ $z_{0}$ values reported in (1) Marticorena et al. (2004), (2) Greeley et al. (1997), and (3) Marticorena et al. (2006).

satellite retrievals for these selected sites suggests the possible merging of the two satellite information to benefit from their complementary strengths, at a global scale, namely the spatial resolution on one side and the robustness to atmospheric contamination on the other side. The mean spatial variability of the PARASOL observations within a $25 \mathrm{~km}$ pixel is of the order of $1 / 4$ of the mean $k_{1} / k_{0}$ value. Using combined PARASOL and ASCAT observations at $6 \mathrm{~km}$ spatial resolution can help delineate fine scale structures that are not captured by ASCAT.

A bi-linear regression is computed between the $z_{0}$ in situ measurements on one hand and the PARASOL $k_{1} / k_{0}$ at $865 \mathrm{~nm}$ and the ASCAT backscattering on the other hand. Figure 5 presents the retrieval versus the in situ $z_{0}$. The calculated regression, representing $72 \%$ of the variance, is as follows:

$\log \left(z_{0}\right)=2.31+0.32 \times \sigma_{0}+0.65 \times k_{1} / k_{0}$.

\section{Aeolian roughness length estimate in arid and semi-arid regions at global scale}

Maps of $z_{0}$ estimates are produced, from ASCAT and PARASOL separately, and from their combination, using the previously established regressions (Fig. 6). Only regions with $z_{0}$ lower than $0.1 \mathrm{~cm}$ are represented, corresponding to arid and semi-arid areas. Note that all regions with topographic features, such as mountains, correspond to high $z_{0}$ as expected. For PARASOL, the averaged 2007-2008 winter observations are considered, as the other periods of the year can be contaminated by aerosols. Snow areas are filtered out, using the National Snow and Ice Data Center (NSIDC, University of Colorado) (Armstrong and Brodzik, 2005). For ASCAT, $z_{0}$
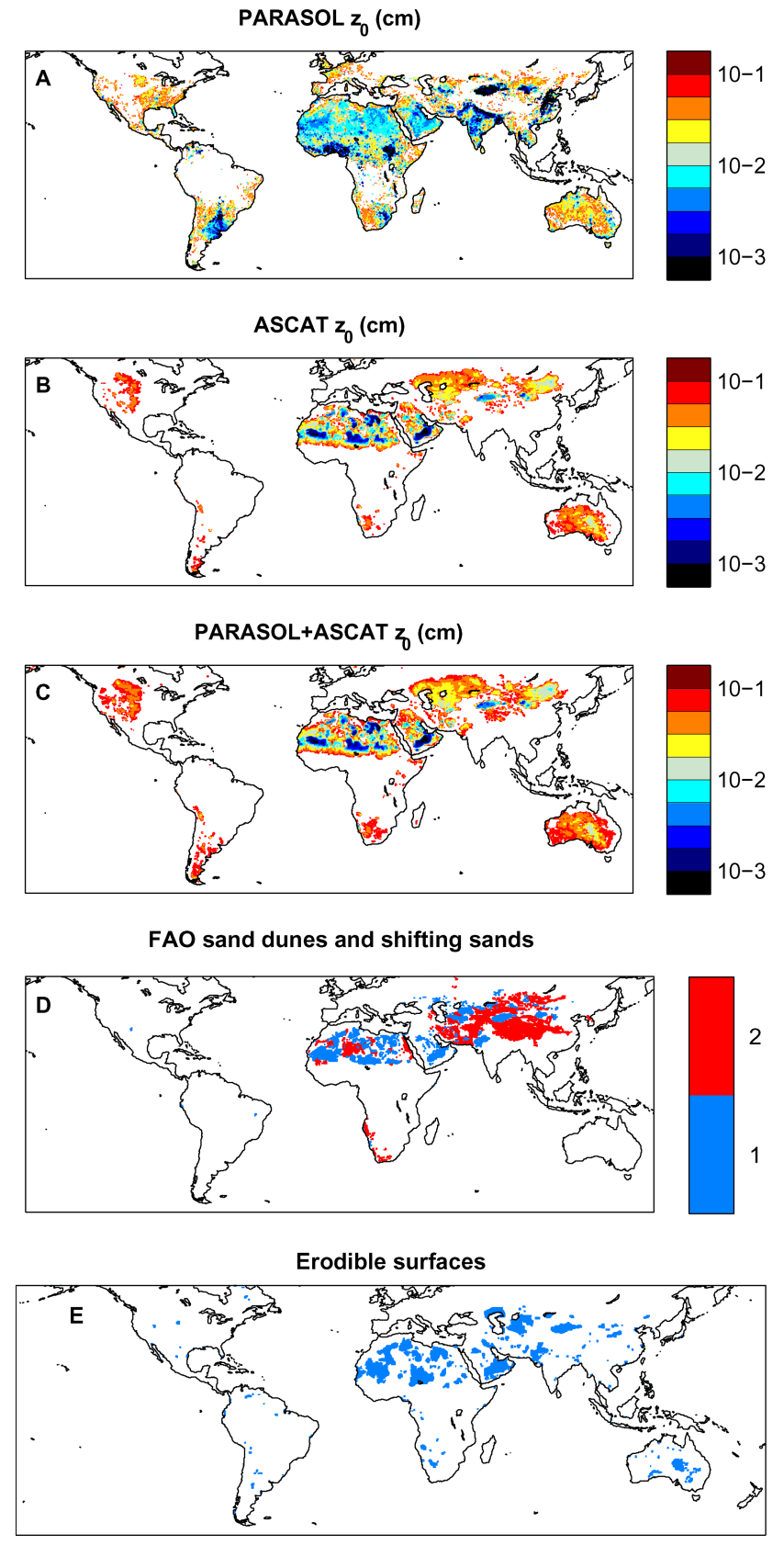

Fig. 6. (A) $z_{0}(\mathrm{~cm})$ estimated from PARASOL only, (B) $z_{0}(\mathrm{~cm})$ estimated from ASCAT only, $(\mathbf{C}) z_{0}(\mathrm{~cm})$ estimated from both PARASOL and ASCAT (when no PARASOL data, $z_{0}$ derived from ASCAT only), (D) map of the FAO for "sand dunes and shifting sands" (blue) and "rock debris and desert detritus" (red) (FAO, 2003), (E) map of the erodible surfaces (Koven and Fung, 2008, Fig. 5a).

is estimated from the yearly average (July 2007-June 2008): this makes it possible to have a better coverage of the areas that are snow covered during the winter, as compared to the PARASOL selection. For the PARASOL-ASCAT combination, the ASCAT data is averaged over the full year, whereas the PARASOL information comes from the winter months 
only, as the PARASOL data for the other months are too noisy. We are aware that the roughness length in arid and semi-arid areas can undergo temporal variability. Vegetation, agriculture practices, or even changes in dune patterns or dust deposition following an aerosol event can affect the roughness length. In a previous study using active microwave only (Prigent et al., 2005), we analyzed the temporal variability of the roughness length. In this study, in order to benefit from the high spatial resolution from the visible, the analysis has to be retricted to November-February, when the atmospheric dust contamination is more limited for the visible observations. The ASCAT data is projected onto the PARASOL grid, using distance-weighted means to the closest neighbors. When the PARASOL observations are not present (because of cloud contamination or snow for instance), $z_{0}$ is retrieved from ASCAT observations only.

The $z_{0}$ derived from PARASOL $(6 \mathrm{~km})$ shows the expected structures over the very arid regions (Fig. 6a), such as the Sahara or the Taklamakan. Similar results were observed by Marticorena et al. (2004) and Laurent et al. (2005). Regions that are likely rather wet, such as India, west China, or west Africa below $10^{\circ} \mathrm{N}$ also produce low $z_{0}$ (note that so far, the $z_{0}$ visible/infrared estimates were not shown in the literature outside the very arid regions). This suggests that the visible/near-infrared observations are sensitive to other surface parameters and cannot provide an unambiguous $z_{0}$ estimate of arid and semi-arid regions globally, without additional filtering.

The $z_{0}$ derived from ASCAT (Fig. 6b) is very close to the $z_{0}$ derived from ERS by Prigent et al. (2005) with $86 \%$ correlation over the globe. A merged PARASOL-ASCAT $z_{0}$ map is produced at $6 \mathrm{~km}$ spatial resolution (Fig. $6 \mathrm{c}$ ). The major spatial structures of the merged PARASOL-ASCAT map are very similar to the ASCAT only map. Note that all erroneous structures present on the PARASOL-only $z_{0}$ estimates are suppressed. The Parasol information does add some small scale variability in the $z_{0}$ estimation that can benefit the modeling activities at high spatial resolution. However, the ASCAT-only dataset can be preferred for some applications, as it can also provide a seasonal variability that Parasol cannot offer because of atmospheric contamination part of the year.

Figure 6d represents the Food and Agriculture Organization classification of some soil types (FAO, 2003). All "dunes and shifting sand" areas delineated by the FAO are clearly observed on Fig. 6c, without any spurious patterns. As expected, all desert regions do not have low roughness length, and rocky deserts for instance such as the Tibetan plateau do not appear on the ASCAT derived map. Note that the threshold value of $0.1 \mathrm{~cm}$ on the roughness length maps corresponds to the mean value plus one standard deviation of the dunes and shifting sand unit, and is consistent with the $z_{0}$ variation range for bare surfaces by Darmenova et al. (2009) (see Table 2 in their paper). Figure 7 (top panel) shows the histograms of the $z_{0}$ derived from the PARASOL-ASCAT
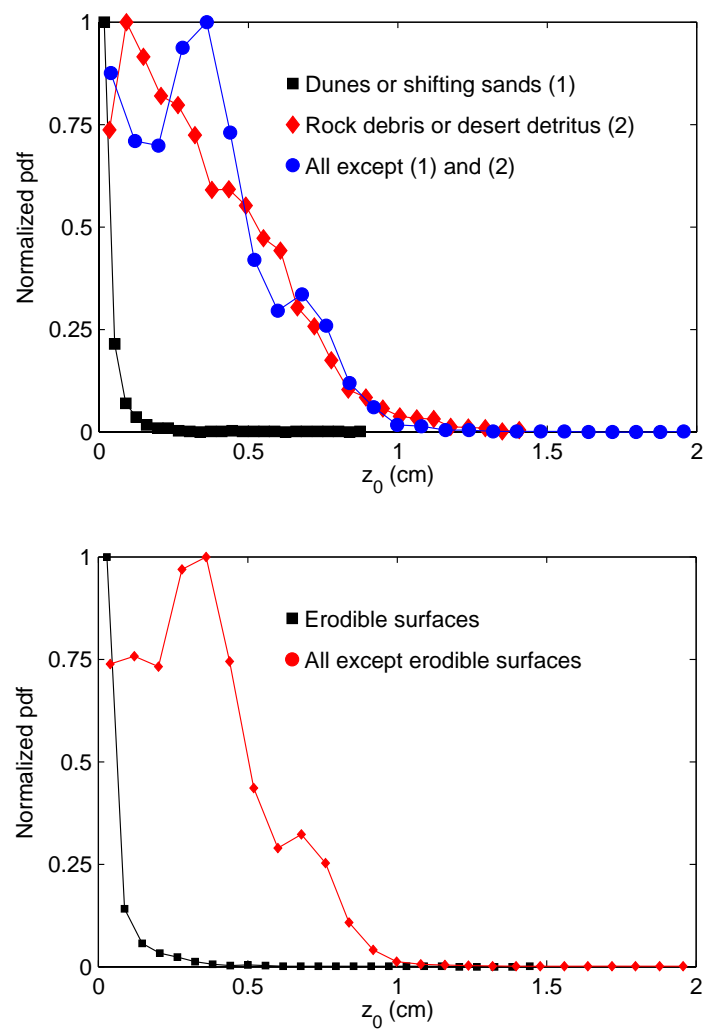

Fig. 7. Top panel: normalized histograms of the PARASOLASCAT $z_{0}$ estimates for "sand dunes and shifting sands" only, for "rock debris and desert detritus" only, and for the remaining FAO classes (FAO, 2003). Bottom panel: normalized histogram of the PARASOL-ASCAT $z_{0}$ estimates for the arid erodible surfaces, as defined by Koven and Fung (2008), as well as for all the remaining surfaces.

combination for "dunes and shifting sands" only (FAO classification), for "rock debris and desert detritus" (FAO classification) only, and for the remaining FAO classes. The sand dunes and shifting sands, as expected, show a very low aeolian roughness length, contrarily to rocky deserts (the two histograms are well separated). The mean value plus one standard deviation of the "dunes and shifting sand" unit is equal to $0.11 \mathrm{~cm}$, consistent with the $z_{0}$ variation range for bare surfaces by Darmenova et al. (2009) (see Table 2 in their paper). Koven and Fung (2008) developed an erodibility index, to characterize wind erodibility as well as dust production. It is based on slope and roughness calculations at $\sim 5 \mathrm{~km}$, using statistics on a Digital Elevation Model at $\sim 30-100 \mathrm{~m}$ scale from the Shuttle Radar Topography Mission. Figure 6e presents this geomorphologically-related index, where non-desert regions are masked (similar to Fig. 5a from Koven and Fung, 2008). The very large dust sources in the Bodélé region, in Malia/Mauritania, in Arabia, or in the Taklamakan appear on both the erodibility maps and as very low aeolian roughness length from PARASOL-ASCAT. In addition, regions of low roughness lengths such as the 
surroundings of Lake Eyre in Australia, the North of the Caspian Sea or South African deserts coincide with erodible areas, as defined by Koven and Fung (2008), although they did not appear on the FAO desert map. Figure 7 (bottom panel) presents the histograms of $z_{0}$ for the erodible surfaces (as in Koven and Fung, 2008) as well as for all surfaces except the erodible ones. The erodible surfaces are clearly associated to very low roughness lengths, without ambiguities with other surface types.

\section{Conclusions}

In this study, we compare the potential of the visible/nearinfrared observations and microwave backscattering measurements from satellite to estimate the aeolian aerodynamic roughness length over arid and semi arid regions, at global scale. We propose to merge the two sources of information to benefit from their complementary aspects, i.e. the high spatial resolution of the visible/near-infrared and the lack of sensitivity to atmospheric contamination of the active microwaves. A global map of the aeolian aerodynamic roughness length at $6 \mathrm{~km}$ resolution is derived from coincident satellite observations and in situ roughness length measurements. It is representative of the northern winter months, when atmospheric contamination is minimum for the visible observations. The results are compared with success with existing information on arid regions. The aeolian roughness length dataset is available to the community, and will be soon tested in global atmospheric dust transport models. For local studies, more detailed analysis could be conducted and the time variability of the satellite information could be studied to examine potential changes of the roughness length with vegetation, humidity or dust events.

The implementation of dust emission models in regional or global models is very challenging. In land surface models, the aerodynamic roughness length is estimated to simulate the wind fields at mesoscales, not to parameterize the dust source at aeolian scales. For instance, in the ECMWF model, an aerodynamic roughness length is set to $1.3 \mathrm{~m}$ in deserts, at least two orders of magnitude larger than the typical values of aeolian roughness length. Efforts are underway to relate these roughness length parameters and possibly harmonize them (Darmenova et al., 2009). In a future study, remote sensing observations will be analyzed to estimate the aerodynamic roughness length for land surface models, and possibly establish consistent scaling between the roughness lengths suitable for dust modeling as well as for momentum transfer in regional to global land surface modeling.
Acknowledgements. We are very grateful to F. M. Bréon for his help in the analysis of the PARASOL observations. We would also like to thank Beatrice Marticorena, Charlie Koven, Bertrand Decharme, and Laurent Menut for valuable discussions and for sharing their datasets.

Edited by: P. Stammes

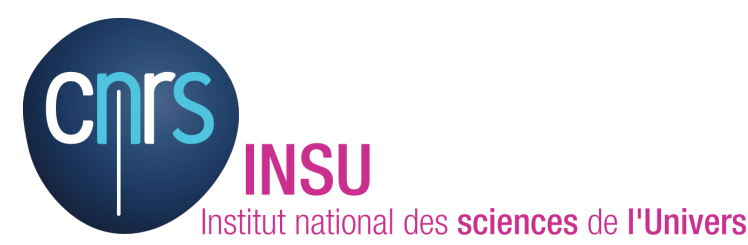

The publication of this article is financed by CNRS-INSU.

\section{References}

Alfaro, S. C. and Gomes, L.: Modeling mineral aerosol production by wind erosion: Emission intensities and aerosol distributions in source areas, J. Geophys. Res., 106, 18075-18084, 2001.

Armstrong, R. L. and Brodzik, M. J.: Northern Hemisphere EASEGrid weekly snow cover and sea ice extent version 3, National Snow and Ice Data Center, Boulder, Colorado, 2005.

Callot, Y., Marticorena, B., and Bergametti, G.: Geomorphological approach for modeling the surface features over arid environments in a model of dust emission: Application to the Sahara desert, Geodyn. Acta, 13, 245-270, 2000.

Darmenova, K., Sokolik, I. N., Shao, Y., Marticorena, B., and Bergametti, G.: Development of a physically based dust emission module within the Weather Research and Forecasting (WRF) model: Assessment of dust emission parameterizations and input parameters for source regions in Central and East Asia, J. Geophys. Res., 114, D14201, doi:10.1029/2008JD011236, 2009.

FAO - Food and Agricultural Organization: The digital Soil map of the world, 1:5 M scale, Land and Water Development Division, FAO, Rome, 2003.

Fung, A. K., Li, Z., and Chen, K. S.: Backscattering from a randomly rough dielectric surface, IEEE T. Geosci. Remote, 30, 356-369, 1992.

Gillette, D. and Passi, R.: Modeling dust emission caused by wind erosion, J. Geophys. Res., 93, 14233-14242, 1998.

Greeley, R., Blumberg, D. G., McHone, J. F., Dobrovolskis, A., Iversen, J. D., Lancaster, N., Rasmussen, K. R., Wall, S. D., and White, B. R.: Applications of space borne radar laboratory data to the study of aeolian processes, J. Geophys. Res., 102, 1097110983, 1997.

Koven, C. D. and Fung, I.: Identifying global dust source areas using high resolution land surface form, J. Geophys. Res., 113, D22204, doi:10.1029/2008JD010195, 2008.

Laurent, B., Marticorena, B., Bergametti, G., Chazette, P., Maignan, F., and Schmechtig, C.: Simulation of the mineral dust emission frequencies from desert areas of China and Mongolia using an aerodynamic roughness length map derived from the POLDER/ADEOS 1 surface products, J. Geophys. Res., 110, D18S04, doi:10.1029/2004JD005013, 2005. 
Laurent, B., Marticorena, B., Bergametti, G., and Mei, F.: Modeling mineral dust emissions from Chinese and Mongolian deserts, Global Planet. Change, 52, 121-141, 2006.

Laurent, B., Marticorena, B., Bergametti, G., Leon, J. F., and Mahowald, N. M.: Modeling mineral dust emissions from the Sahara desert using new surface properties and soil database, J. Geophys. Res., 113, D14218, doi:10.1029/2007JD009484, 2008.

Leroy, M., Deuzé, J. L., Bréon, F. M., Hautecoeur, O., Herman, M., Buriez, J. C., Tanre, D., Boufiés, S., Chazette, P., and Roujean, J. L.: Retrieval of aerosol properties and surface bi- directional reflectances from POLDER/ADEOS, J. Geophys. Res., 102, 17023-17037, 1997.

Lettau, H.: Note on aerodynamic roughness-parameter estimation on the basis of roughness-element description, J. Appl. Meteorol., 8, 828-832, 1969.

MacKinnon, D. J., Clow, G. D., Tigges, R. K., Reynolds, R. L., and Chavez Jr., P. S.: Comparison of aerodynamically and modelderived roughness lengths $\left(z_{0}\right)$ over diverse surfaces, central Mojave Desert, California, USA, Geomorphology, 63, 103-113, 2004.

Maignan, F., Bréon, F. M., and Lacaze, R.: Bidirectional reflectance of Earth targets: evaluation of analytical models using a large set of spaceborne measurements with emphasis on the hot spot, Remote Sens. Environ., 90, 210-220, 2004.

Marticorena, B. and Bergametti, G.: Modeling the atmospheric dust cycle: 1 . Design of a soil-derived dust production scheme, J. Geophys. Res., 100, 16415-16430, 1995.

Marticorena, B., Bergametti, G., Aumont, B., Callot, Y., NaDoumi, C., and Legrand, M.: Modeling the atmospheric dust cycle: 2. Simulation of Saharan dust sources, J. Geophys. Res., 102, 4387-4404, 1997.

Marticorena, B., Chazette, P., Bergametti, G., Dulac, F., and Legrand, M.: Mapping the aerodynamic roughness length of desert surfaces from the POLDER/ADEOS bi-reflectance product, Int. J. Remote Sens., 25, 603-626, 2004.

Marticorena, B., Kardous, M., Bergametti, G., Callot, Y., Chazette, P., Khatteli, H., Le Hegarat-Mascle, S., Maille, M., Rajot, J.L., Vidal-Madjar, D., and Zribi, M.: Surface and aerodynamic roughness in arid and semiarid areas and their relation to radar backscatter coefficient, J. Geophys. Res., 111, F03017, doi:10.1029/2006JF000462, 2006.

Prigent, C., Tegen, I., Aires, F., Marticorena, B., and Zribi, M.: Estimation of the aerodynamic roughness length in arid and semiarid regions over the globe with the ERS scatterometer, J. Geophys. Res., 110, D09205, doi:10.1029/2004JD005370, 2005.
Raupach, M., Gillette, D., and Leys, J.: The Effect of Roughness Elements on Wind Erosion Threshold, J. Geophys. Res., 98, 30233029, 1993.

Roujean, J.-L., Leroy, M., and Deschamps, P.-Y.: A bidirectional reflectance model of the Earth's surface for the correction of remote sensing data, J. Geophys. Res., 97, 20455-20468, 1992.

Roujean, J.-L., Tanré, D., Bréon, F. M., and Deuzé, J.-L.: Retrieval of land surface parameters for GCM from POLDER bidirectional measurements during HAPEX-Sahel, J. Geophys. Res., 102, 11201-11218, 1997.

Shao, Y.: A model for mineral dust emission, J. Geophys. Res., 106, 20239-20254, 2001.

Sherman, D. J. and Farrell, E. J.: Aerodynamic roughness lengths over movable beds: Comparison of wind tunnel and field data, J. Geophys. Res., 113, F02S08, doi:10.1029/2007JF000784, 2008.

Tanré, D., Bréon, F. M., Deuzé, J. L., Dubovik, O., Ducos, F., François, P., Goloub, P., Herman, M., Lifermann, A., and Waquet, F.: Remote sensing of aerosols by using polarized, directional and spectral measurements within the A-Train: the PARASOL mission, Atmos. Meas. Tech., 4, 1383-1395, doi:10.5194/amt-4-1383-2011, 2011.

Tegen, I., Koch, D., Lacis, A. A., and Sato, M.: Towards a global aerosol climatology: preliminary trends in tropospheric aerosol amounts and corresponding impact on radiative forcing between 1950 and 1990, J. Geophys. Res., 105, 26971-26990, 2000.

Todd, M., Bou Karam, D., Cavazos, C., Bouet, C., Heinold, B., Baldasano, J., Cautenet, G., Koren, I., Perez, C., Solmon, F., Tegen, I., Tulet, P., Washington, R., and Zakey, A.: Quantifying uncertainty in estimates of mineral dust flux: An inter-comparison of model performance over the Bodélé Depression, Northern Chad, J. Geophys. Res., 113, D24107, doi:10.1029/2008JD010476, 2008.

Uno, I., Wang, Z., Chiba, M., Chun, Y. S., Gong, S. L., Hara, Y., Jung, E., Lee, S.-S., Liu, M., Mikami, M., Music, S., Nickovic, S., Satake, S., Shao, Y., Song, Z.,Sugimoto, N., Tanaka, T., and Westphal, D. L.: Dust model intercomparison (DMIP) study over Asia: Overview, J. Geophys. Res., 111, D12213, doi:10.1029/2005JD006575, 2006.

Xian, X., Tao, W., Qingwei, S., and Weimin, Z.: Field And WindTunnel Studies Of Aerodynamic Roughness Length, Bound.Lay. Meteorol., 104, 151-163, 2002. 